\title{
Observations on gastric acid output by a three- hour histamine infusion test using maximal doses on patients with duodenal ulcer and in normal controls
}

\author{
R. M. HECTOR AND J. F. WEBB \\ From the Cambridge Military Hospital, Aldershot
}

SUMMARY The results of a series of histamine infusion tests extended over a period of three hours in 100 patients with duodenal ulcer and in 30 normal controls showed that while in the $\frac{3}{8}$ former group acid secretion continued to rise hourly both quantitatively and qualitatively $\stackrel{\Phi}{\sim}$ throughout each of the three-hour periods of the tests, this did not occur in the normal controls $\vec{\varphi}$ in whom acid secretion levelled off during the second hour. Assay of 30-minute aspirates in the. duodenal ulcer group showed that the 90-120 minute specimen (doubled) gave a close approximation to the values obtained during the third hour and represents maximal acid secretion of the gastric mucosa.

The continuous intravenous infusion of histamine acid phosphate in 'maximal doses'(Lawrie, Smith, and Forrest, 1964) is the most effective method of inducing the stomach to secrete acid over a prolonged period, for subsequent assay, by this agent. However, there are special factors in the technique which exert an important influence on the results obtained and which require emphasis; these include the position of the patient during aspiration, the type of tube used, its siting, the necessity for clearing any tubal blockage as soon as it occurs, and the duration of the test.

It had been found by Lawrie et al (1964) that the values of gastric juice and concentration of acid gradually rise until they reach a steady state shortly after the first hour of the infusion. Wyllie and Smith (1965) found that acid production levelled off about 30 to 45 minutes after the beginning of the infusion. Christiansen and Køster (1965), on the other hand, found that the plateau of acid secretion did not occur until late in the second hour of infusion.

There appeared, therefore, to be grounds for carrying out a series of histamine infusion tests over a period of three hours to study the mean trend of acid production both qualitatively and quantitatively in patients with duodenal ulcer and in normal controls. A further objective was to

Received for publication 10 December 1969. determine the optimum time for the withdrawal $\frac{\overline{0}}{3}$ of the specimen of gastric juice in patients with $\supset$ duodenal ulcer to assess maximal acid output in view of conflicting opinions as to when this specimen should be withdrawn.

\section{Material and Methods}

Histamine infusion tests each lasting three hours $\frac{7}{0}$ were carried out on 100 male patients with duodenal ulcer (age range 17-46, mean 27 years) in $\widetilde{N}$ whom hiatus hernia had been excluded and on $N$ 30 normal controls (age range 17-36, mean $23 \stackrel{\mathrm{N}}{\mathrm{N}}$ years). Aspiration was performed by a naso- 0 fundal tube of French gauge 16 or 14 passed through the nose and positioned without fluoro- $\frac{-}{D}$ scopy by introducing it to between the two ringed positions marked on the tube appropriate to the patient's height (Hector, 1968 and 1969). Once aspiration had begun a further minor $\stackrel{\otimes}{\circ}$ adjustment of tube length was made if required. The patient was positioned lying in the left $\frac{\varrho}{\sigma}$ posterior oblique position and the lower end of the bed was raised upon 12-inch blocks so that $\delta$ gastric juice gravitated to the left side of the fundus. When positioned in this manner the tube

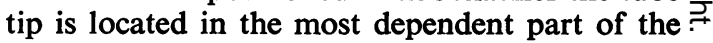


fundus being deflected to this site by the oesophago-gastric angle. As the tube has only two eyes located close to its tip it will withdraw all available gastric juice in contrast to some conventional tubes which, having eyes over the distal three or more inches, will only aspirate to the proximal eye, thus leaving a large residue of untapped fluid. By aspirating from this site no problem is created by the many different lengths, tones, and types of stomach; thus the cup and spill type of stomach presents no problem.

Histamine acid phosphate was infused intravenously by a Palmer pump in an hourly dosage of $40 \mu \mathrm{g} / \mathrm{kg} /$ hour. An intramuscular injection of $50 \mathrm{mg}$ mepyramine maleate was given before the start of the infusion and repeated once if indicated. Care was taken to clear any blockage in the tube by injecting air down it from a $20 \mathrm{ml}$ syringe permanently attached by a needle to the rubber hose connecting the tube to the suction pump. Suction was maintained at a negative pressure of $60-70 \mathrm{~cm}$ of water. Aspirate was collected into a $250 \mathrm{ml}$ graduated glass cylinder which enabled the nurse to judge the efficacy of aspiration at any given time. The resting juice was aspirated, measured, and discarded, and thereafter specimens were withdrawn for titration of total acids colorimetrically using phenolphthalein to $p \mathrm{H} \mathrm{9.0.}$

Hourly aspirates were withdrawn from the 30 normal controls and from the first 44 patients with duodenal ulcer; however, as it was noted that both the volume and acidity of the gastric juice showed mean increases progressively throughout each of the three hours, it was considered that 30-minute aspirates might provide more information and this was done in the subsequent 56 patients.

\section{Results}

STATISTICAL ANALYSIS OF HOURLY ASPIRATES

The mean values of hourly aspirates over a period of three hours in 30 controls and 100 patients with duodenal ulcer are shown in Figure 1. Table I shows the statistical analysis of

\begin{tabular}{llcc}
\hline & $\begin{array}{l}\text { Total Output } \\
(\mathrm{ml} / \mathrm{hr})\end{array}$ & $\begin{array}{l}\text { Total Acidity } \\
(\mathrm{m} \text {-equiv/l/hr) }\end{array}$ & $\begin{array}{l}\text { Total Acid } \\
\text { Output }(\mathrm{m}- \\
\text { equiv/spec/hr }\end{array}$ \\
\hline Increase (\%) & 4 & 1.9 & 5.8 \\
Mean difference & 14.3 & 2.42 & 2.7 \\
SD of mean difference & 3.624 & 0.84 & 0.536 \\
t & 3.98 & 2.88 & 5.02 \\
P & $<0.001$ & $<0.01$ & $<0.001$ \\
\hline
\end{tabular}

Table I Statistical analysis of the increases obtained in the third hourly aspirate over those of the second hour in total output, total acidity, and total acid output in 100 patients with duodenal ulcer the increases obtained in the third hour of aspiration in the patients with duodenal ulcer.

Thus whatever criterion be used to determine

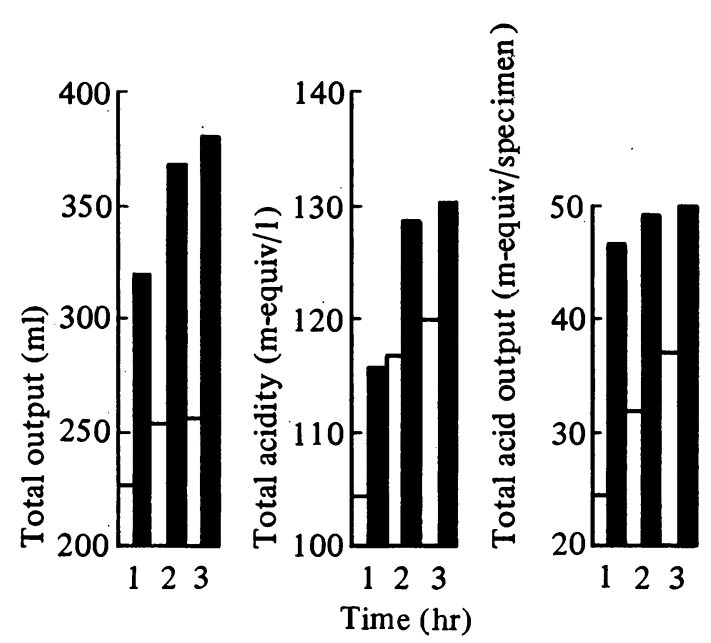

Fig. 1 Mean values of hourly aspirates over a period of three hours as total output, total acidity, and total acid output in 30 normal controls and in 100 patients with duodenal ulcer (shaded area).

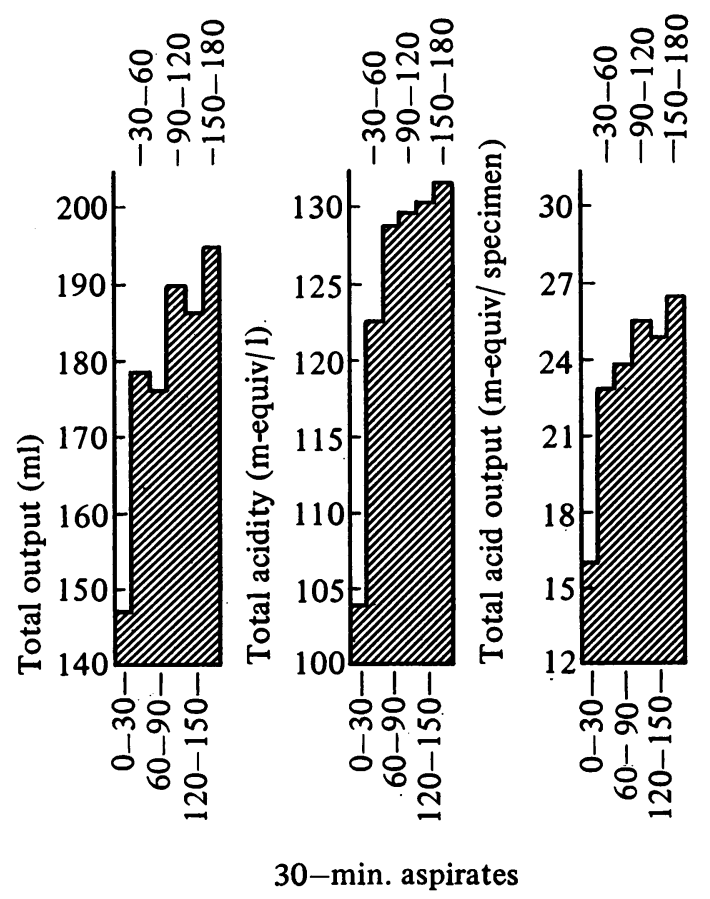

Fig. 2 Mean values of total output, total acidity, and total acid output per 30-minute aspirate over a period of three hours in 56 patients with duodenal ulcer. 
the optimum point for the withdrawal of gastric juice in patients with duodenal ulcer the increases in the third hour are statistically significant. These increases are, however, small, and continuation of the test through the third hour would not be justifiable if the value obtained from an earlier specimen in m-equiv/specimen (doubled) could be shown to approximate to that of the third hour. With this end in view 30 -minute aspirates were withdrawn from the remaining 56 patients with duodenal ulcer and the results are shown in Figure 2.

Consideration of the mean values from the 30-minute aspirates suggests that the differences between the aspiration taken between 150 and 180 minutes and the values of the aspirate taken between 90 and 120 minutes (the next highest in two of the three values) were small.

STATISTICAL ANALYSis OF 30-MinUte ASPIRATES

The statistical analysis of the increases obtained in aspirates between 150 and 180 minutes over those taken between 90 and 120 minutes are shown in Table II.

\begin{tabular}{llll}
\hline & $\begin{array}{l}\text { Total Output } \\
(\mathrm{ml} / 30 \mathrm{~min})\end{array}$ & $\begin{array}{l}\text { Total Acidity } \\
\text { (m-equiv/l/ } \\
30 \text { min) }\end{array}$ & $\begin{array}{l}\text { Total Acid } \\
\text { Output }(\mathrm{m}- \\
\text { equiv/spec/ } \\
30 \mathrm{~min})\end{array}$ \\
\hline Increase (\%) & 2.4 & 4.2 & 1 \\
Mean difference & 4.84 & 1.0 & 0.8 \\
SD of mean difference & 2.67 & 0.45 & 1.2 \\
t & 1.80 & 2.27 & 0.7 \\
P & $>0.05$ & $>0.01$ & $>0.4$ \\
\hline
\end{tabular}

Table II Statistical analysis of the increases obtained in the 150-180 minute aspirate over those of the 90-120 minute aspirate as the mean values for total output, total acidity, and total acid output in 56 patients with duodenal ulcer

Thus the value of the calculated total acid output based upon the 90-120 minute aspirate (doubled) is $50.4 \mathrm{~m}$-equiv/specimen compared with the actual value of $50.9 \mathrm{~m}$-equiv/specimen obtained for the whole of the third hourly aspirate. This shows the similarity of results of total acid output in m-equiv/specimen between the 90-120 minute aspirate (doubled) and that of the third hour of the test.

From the above figures it would appear reasonable to accept the 90-120 minute period of aspiration in patients with duodenal ulcer as a reliable indicator of maximal acid output potential of the gastric mucosa. This contrasts with the findings of Lawrie et al (1964) and of the Multicentre Pilot Study (1967) which indicated that plateau responses were generally not fully established until about one hour after the start of the infusion.

A comparison between the result of maximal total acid output in m-equiv/specimen/hr in this paper with those of some other published figures

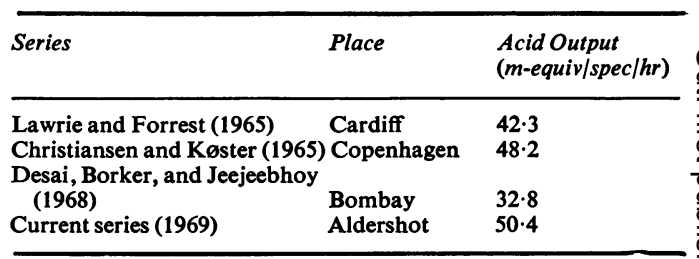

Table III Comparison of acid output in previous series and in the present study

of histamine infusion tests is shown in Table III. $\stackrel{\vec{\omega}}{\circ}$ But these results are not strictly comparable for $\stackrel{Q}{C}$ the following reasons. (1) The age groups of patients in the other series were wider and $\overrightarrow{.}$ included a number of older and female patients $\vec{N}$ in whom acid output is known to be lower. (2) The ethnic groups examined by Desai, Borker, $\stackrel{f}{\circ}$ and Jeejeebhoy (1968) are stated by them to have $\frac{9}{5}$ a smaller parietal cell mass than those found in $\vec{\nabla}$ western countries. (3) In the current series $\mathbb{D}$

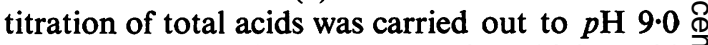
as against $p \mathrm{H} 7 \cdot 0$ in the other series which could tend to favour the former by up to $2 \mathrm{~m}$-equiv/l/hr $\mathbb{\Phi}$ or under $1 \mathrm{~m}$-equiv/specimen/hour.

\section{Discussion}

Our mean results of histamine infusion tests in patients with duodenal ulcer differ from those of Lawrie et al (1964) in that acid production continued to rise hourly throughout the three hours of the test, and we were unable to demonstrate that the steady state occurred during the test period. Statistical analysis of the differences of $\subsetneq$ values obtained in the third hour over those of the second hour confirms that they are significantly higher.

Consideration of 30 -minute specimens in patients with duodenal ulcer supports our belief 의 that the withdrawal of a specimen too early in the $D$ test may lead to underestimation of the potential of the gastric mucosa to secrete acid, due to the N fact that the concentration of acid continues to rise.

It was shown that the 90-120 minute specimen (doubled) gave a close approximation to the output of the whole of the third hour in m-equiv/ $O$ specimen and was therefore considered to be a satisfactory 'yardstick' for measuring maximal acid production. Normal controls appeared to reach the steady state of acid production early in the second hour as found by Lawrie et al (1964). Thus the behaviour of the gastric mucosa in its production of acid differed considerably in patients with duodenal ulcer and in normal controls in that in the former group acid production is much greater both quantitatively and qualitatively. 
We should like to record our thanks to the nursing staff who conducted the tests, to $\mathrm{Mr} \mathrm{T}$. Williamson who carried out the titrations in the Leishman Laboratory of the Cambridge Military Hospital, and to Mr A. H. Gould, statistician, Ministry of Defence, who carried out the statistical analysis.

References

Christiansen, P. M., and Køster, K. H. (1965). Histamine infusion test. Lancet, 2, 1189-1190.
Desai, H. G., Borkar A. V., and Jeejeebhoy, K. N. (1968). Acid output in histamine infusion test in duodenal ulcer patients. Digestion, 1, 115-119.

Hector, R. M. (1968). Improved technique of gastric aspiration. Lancet, 1, 15-16.

Hector, R. M. (1969). Gastric aspiration. Gut, 10, 598.

Lawrie J. H., Smith, G. M. R., and Forrest, A. P. M. (1964), The histamine infusion test. Lancet, 2, 270-273.

Lawrie J. H., and Forrest, A. P. M. (1965). The measurement of gastric acid. Postgrad. Med. J., 41, 408-417.

Multicentre Pilot Study. (1967). Pentagastrin as a stimulant of maximal gastric acid response in man. Lancet, 1, 291-295.

Wyllie, J. H., and Smith, G. (1965). Histamine infusion test. Lancet, 2, 823-824.
(1) 